\title{
Knowledge, prevalence and treatment practices of uterine prolapse among women of reproductive age in the Jhaukhel- Duwakot Health Demographic Surveillance Site, Bhaktapur, Nepal
}

\section{Shrestha $B^{1}$, Onta $S^{2}$, Choulagai $B^{3}$, Shrestha KB', Petzold $M^{5}$, Krettek $A^{6}$}

'Binjwala Shrestha, Department of Community Medicine and Public Health, Institute of Medicine, Tribhuvan University, Kathmandu, Nepal; Department of Internal Medicine and Clinical Nutrition, Institute of Medicine, Sahlgrenska Academy at University of Gothenburg, Sweden; ${ }^{2}$ Sharad Onta, Department of Community Medicine and Public Health, Institute of Medicine, Tribhuvan University, Kathmandu, Nepal; ${ }^{3}$ Bishnu Choulagai, Department of Community Medicine and Public Health, Institute of Medicine, Tribhuvan University, Kathmandu, Nepal; Department of Internal Medicine and Clinical Nutrition, Institute of Medicine, Sahlgrenska Academy at University of Gothenburg, Sweden; ${ }^{4}$ Khadga B Shrestha, Department of Community Medicine and Public Health, Institute of Medicine, Tribhuvan University, Kathmandu, Nepal; ${ }^{5}$ Max Petzold, Health Metrics at Sahlgrenska Academy, University of Gothenburg, Sweden; School of Public Health, Faculty of Health Sciences, University of the Witwatersrand, Johannesburg, South Africa; ${ }^{6}$ Alexandra Krettek, Department of Internal Medicine and Clinical Nutrition, Institute of Medicine, Sahlgrenska Academy at University of Gothenburg, Sweden; Biomedicine and Public Health Department, School of Health and Education, University of Skövde, Sweden; Department of Community Medicine, Faculty of Health Sciences, The Arctic University of Norway, Troms $\varnothing$, Norway.

\begin{abstract}
Background: Uterine prolapse (UP) is a main contributor to reproductive health problems that influence women's quality of life. In Nepal, the UP prevalence ranges from 7-27\%. Women experience various difficulties and symptoms due to UP, which are determined by the type as well as thestage of UP.

Objectives: This study aimed to explore the knowledge, prevalence and treatment practices of uterine prolapse among women of reproductive age in the peri-urban Jhaukhel-Duwakot Health Demographic Surveillance Site (JD-HDSS) in the Bhaktapur district of Nepal.

Methods: This cross-sectional study collected data in two stages. A structured survey of 3,124 households in JD-HDSS, incorporating $60 \%$ of all women of reproductive age, assessed knowledge of uterine prolapse and identified self-reported disease prevalence (symptomatic). Next, we organised a five day clinical screening camp at JD-HDSS to identify the prevalence of uterine prolapse in attendees.The household survey was conducted on September-December 2012 and the UP screening camp on May-June 2013. Descriptive statistics was used to analyse the proportion of comprehensive knowledge regarding UP and the prevalence of UP.

Results: Ninety-three percent of womenin JD-HDSS had heard of uterine prolapse and $55 \%$ of those had comprehensive knowledge. Self-reported (symptomatic) prevalence was $2.11 \%$ (8.5\% including women who had undergone hysterectomy for uterine prolapse). Among these, $52.6 \%$ had received no treatment. The most common reported treatments of uterine prolapse included surgery $(53.2 \%)$, exercise and medicine $(35.5 \%)$ and pessary $(11.3 \%)$. Among women attending the outreach camp ( $\mathrm{N}=303)$, UP prevalence was $15.18 \%$.

Conclusion: Knowledge of uterine prolapse among women in JD-HDSS is almost double that reported in a national survey. Similarly, the prevalence of self-reported uterine prolapse in JD-HDSS is almost three fold less than the national prevalence. Knowledge,early healthcare practices and availability of surgical care for uterine prolapse might have contributed to these findings.
\end{abstract}

Key words: Uterine prolapse, Knowledge, Prevalence, Treatment practices, Nepal

Address for correspondence

Binjwala Shrestha

Department of Community Medicine and Public Health

Institute of Medicine, Tribhuvan University, Kathmandu, Nepal

E-mail: binjwala.shrestha@gu.se

\section{INTRODUCTION}

T terine prolapse (UP) is a main contributor to reproductive health problems that influences women's quality of life'. Generally, slippage of the pelvic 
organs, i.e. uterus, rectum, bladder, is described as pelvic organ prolapse (POP). Symptoms for these types of prolapse include adragging sensation, vaginal lump, or organ protrusion into the vagina ${ }^{2}$. Although women understand that pelvic organ prolapse induces various difficulties and symptoms, most perceive UP as the cause $^{3}$. Indeed more than $85 \%$ of women contend with physical discomforts, e.g. difficulty walking, standing, working, sitting and lifting, resulting from uterine bulging. Furthermore, urinary and bowel symptoms are common ( $68 \%$ and $42 \%$, respectively), and many women have difficulty with sexual activity ${ }^{2}$. Severity of the symptoms depends upon the progression of UP, i.e. first stage (mild), second stage (moderate) and third stage (severe) ${ }^{4}$. Another study reported that $50 \%$ of women will develop UP along with prolapse of other pelvic organs, e.g. bladder and rectum, but only $10 \%$ to $30 \%$ will seek health care for these conditions ${ }^{5}$.

In Nepal, the prevalence of clinically diagnosed UP ranges from $17 \%$ to $27 \%$, and seven percent of all cases are self-reported ${ }^{6}$. A hospital-based study of UP prevalence reported low numbers in comparison to screening camp data. During a three-month prospective study in Kathmandu, UP affected only 94 of 3,616 (2.6\%) women who attended the gynaecological outpatient clinic at Tribhuvan University Teaching Hospital'. Another hospital-based study reported $9.6 \%$ UP prevalence among 1,147 gynaecological patients in a maternity hospital ${ }^{8}$.

In Nepal, family planning services and maternal health care are universally accessible in public health facilities ${ }^{9}$. Although the government as well as nongovernmental organizations have conducted continuous UP-specific awareness programs in Nepal since 2005 , we recently reported that $52.9 \%$ of Nepalese women lack knowledge of UP, and only $37.5 \%$ exhibit comprehensive knowledge about this condition ${ }^{10}$. The lack of appropriate knowledge and inadequate access to information regarding prevention may delay care and safety measures ${ }^{11}$. The current study therefore aimed to explore UP knowledge, prevalence and treatment practices among women of reproductive age in the Jhaukhel-Duwakot Health Demographic Surveillance Site (JD-HDSS) in the Bhaktapur district of Nepal. Our findings will be useful to understand knowledge, prevalence and treatment practices, and aid the development of evidence-based strategies for awareness and UP treatment programs for both primary and secondary prevention.

\section{METHODS}

\section{STUDY DESIGN AND SETTING}

Located in the mid-hills of the Bhaktapur district, 13 kilometres outside Kathmandu the capital city of Nepal, Duwakot and Jhaukhel are two village development committees (VDCs). Our cross-sectional study design identified the prevalence, knowledge and practices of UP in the JD-HDSS, which operates as a collaborative effort by the University of Gothenburg and the Nordic School of Public Health NHV, Sweden, and Kathmandu Medical College (KMC) and Nepal Medical College (NMC), Nepal'2.

\section{STUDY PARTICIPANTS}

Study participants were women of reproductive age (15 to 49 years). A census conducted among all JD-HDSS households revealed a total of 5,169 women in this age group. Simple random sampling was applied to select 3,124 interviewees (60.4\%) for the household survey, one woman from each household. Following the household survey, we organised a UP screening camp to identify the prevalence of UP. Women who attended $(\mathrm{N}=303)$ the screening camp were included as study participants.

\section{STUDY TOOLS}

To facilitate understanding for study participants, we translated UP as "Patheghar jharne" in the local Nepali language. We used a standardized tool including 12 statements regarding UP signs, symptoms, risk factors, treatment options and preventive measures to assess participants' knowledge of UP ${ }^{13}$. For clinical examination, we used a POP questionnaire ${ }^{14}$ to assess symptoms and signs of UP according to prolapse of the pelvic organ in the anterior, posterior or middle compartment of the pelvic floor. Tools were translated into Nepali language and adapted to the local context. After pre-testing the questionnaire at Kharipati village closely located to Jhaukhel, we finalized the tool by modifying words and question sequence.

\section{DATA COLLECTION}

Trained female enumerators, most with health backgrounds such as auxiliary health worker, auxiliary midwife and the social sciences background, conducted a structured interview. All enumerators received two days of training regarding the technical aspects of UP, including signs, symptoms and difficulties relating to UP. The study was conducted in two phases. First, we conducted a survey of 3,124 households to identify socioeconomic characteristics, UP knowledge and prevalence of self-reported UP including treatment 
practices. During data collection, four field supervisors were recruited for close supervision of data collection. To ensure quality of the data, one author (BS) visited the location and provided feedback to supervisors and enumerators. Data was collected between September and December 2012.

Second, we organised a five-day UP screening camp with clinical examinations to identify the prevalence of UP. All female community health volunteers from all nine wards of JD-HDSS participated. Local health workers were mobilized to inform and encourage women to attend the UP screening camp, which was conducted by a team of gynaecologists from KMC and NMC during May and June 2013.

\section{DATA ANALYSIS}

\section{Household survey to assess knowledge of UP}

Data were entered in EpiData Manager, version 1.4 and statistical analyses were conducted with the Statistical Package for Social Sciences (SPSS), version 17.0 (SPSS Inc., Chicago, Illinois, USA). We used descriptive statistics to describe the socioeconomic characteristics of study participants and their spouses. The proportion of knowledge was computed according to the correct answer for each item of the assessment tool. Next, we described the level of knowledge of UP in categories of 12 variables, as recommended to assess knowledge of POP, we scored correct answers as "1" and "incorrect" and "don't know" answers were scored as "0"13. We calculated the mean values of all 12 variables of knowledge assessment. We considered the value of mean and above mean as comprehensive knowledge of UP.

\section{Analysis of UP prevalence (self-reported and clinical diagnosis)}

Data from the household interview regarding selfreported reproductive health problems, including UP and its treatment practices, were analysed separately, detailing the socioeconomic characteristics, UP prevalence (self-reported) and treatment practices of UP. Similarly, socioeconomic characteristics of the participants at the UP screening camp were also described.

\section{Calculation of UP prevalence and treatment practice for UP}

Self-reported UP prevalence was calculated using the total number of women who reported UP symptoms in the household survey. Clinically diagnosed UP prevalence was calculated using the total number of
UP and POP diagnoses among women who attended the UP screening camp. Women who had undergone surgical treatment (hysterectomy for UP) were excluded in both calculations.

\section{ETHICAL CONSIDERATIONS}

Reproductive health is considered a private matter in the Nepalese society, particularly among women. Therefore, we discussed and ensured respondents' autonomy and confidentiality prior to each interview. We also explained the background and aim of the study to each participant, and conducted interviews only after obtaining informed consent. This study was granted ethical approval by the Nepal Health Research Council (Reg. no. 56/2012).

\section{RESULTS}

\section{KNOWLEDGE OF UP AMONG WOMEN OF REPRODUCTIVE AGE IN BHAKTAPUR DISTRICT}

\section{Socioeconomic characteristics}

A total of 3,124 women $(60 \%$ of the total population of women of reproductive age) participated in the household survey, $60 \%$ from Duwakot and $40 \%$ from Jhaukhel. The dominant ethnic group in Jhaukhel was Newar (42.5\%), compared with Bramhin/Chhetri (43.1\%) in Duwakot. Participants were distributed almost equally among the first to fourth wealth quintiles (range $24.4 \%$ to $26.1 \%$ ) (Table1).

Among married participants (85\%), 56.2\% were currently living with their spouse and $48.5 \%$ used contraception. The mean age at marriage for women was $19.1 \pm 3.4$ years and the mean age of first pregnancy was 20.1 \pm 3.7 years. On average, women had $2.3 \pm 1.3$ children. A majority of women (39.3\%) belonged to the 20 to 30 year age group, followed by the 31 to 40 year age group (36.6\%). The women's mean age was 31.9 \pm 8.2 years, compared with $37.1 \pm 8.4$ years for their spouse. Education level differed among women and men: $21.4 \%$ of the women and none of the men were illiterate. Moreover, men were more educated than women at each level of education. More men $(53.2 \%)$ than women $(23.7 \%)$ were employed in the formal sector (regular job) (Table 2). Men made most (52\%) household decisions.

\section{Knowledge of UP}

A majority (93\%) of respondents had heard of UP and among them, 92.15\% understood that carrying heavy loads can increase the probability of UP. Similarly, $84 \%$ to $88.7 \%$ of participants had knowledge regarding 
risk factors (delivering many children), symptoms of UP (feeling of heaviness/bulging sensation)and appropriate method of diagnosis of UP (health checkup). Regarding age as contributing factor, $64.2 \%$ of participants perceived that UP can affect women at any age. However, $41.8 \%$ perceived that elderly women experience symptoms of POP (vaginal, urinary and bowel symptoms) more frequently than women in the reproductive age group. Perceived treatment options for UP varied from $49 \%$ to $59.5 \%$, including regular exercise (56.4\%), vaginal hysterectomy (59.5\%) and ring pessary (49.7\%). Regarding diagnostic method, $31 \%$ of women perceived that a blood test is one method of UP diagnosis, $23.15 \%$ perceived that UP is incurable and $13.8 \%$ did not know that obesity is a risk factor for UP (Table 3).

\section{PREVALENCE OF UP AND REPORTED TREATMENT PRACTICES DURING HOUSEHOLD SURVEY AND SCREENING CAMP}

\section{Socioeconomic background of participants who reported reproductive health problems during household survey}

During the household survey, 487 participants reported that they had reproductive health problems, 59.7\% from Duwakot and $40.3 \%$ from Jhaukhel. Among these, $61.2 \%$ were Bramhin/Chhetri and 31\% were Newar; $36.8 \%$ were between 30 and 39 years of age (Table 4).

\section{Socioeconomic background of UP screening camp service users}

Altogether, 303 women attended the five-day UP screening camp in JD-HDSS, including 58\% from Duwakot and 42\% from Jhaukhel. Regarding caste/ ethnic group, 50\% were Bramhin/Chhetri and 41.3\% were Newar. Thirty-four percent were between 30 and 39 years of age (Table 4 ).

\section{Self-reported (symptomatic) UP prevalence and treatment practices}

The UP prevalence based on self-reported data from 3,124 women who participated in the household survey was $2.11 \%$ (8.5\% including women who had undergone hysterectomy for UP). Among them, 46.4\% reported that they had received UP treatment from hospitals in Bhaktapur and Kathmandu, including surgery (53.2\%), exercise and medicine (35.5\%) and pessary (11.3\%) (Table 5).

\section{UP prevalence with clinical diagnosis and treatment practices}

In women who attended the UP camp $(\mathrm{N}=303)$, the prevalence of clinically diagnosed UP was $15.18 \%$ (23.1\% including women who had undergone hysterectomy for UP). Among these, 59.3\% exhibited POP (UP with cystocele and rectocele), $25.6 \%$ had UP and $5 \%$ had vault prolapse. Regarding treatment practices for UP, $84.3 \%$ $(\mathrm{N}=70)$ received treatment from hospitals in Bhaktapur and Kathmandu, including surgery (34.3\%) and pessary (37.1\%), compared with $28.6 \%$ who used exercise and medicine (Table 5).

Table 1: Distribution of socioeconomic characteristics of participants in a household survey in the JhaukhelDuwakot Health Demographic Surveillance Site $(\mathbf{N}=3,124)$

\begin{tabular}{|c|c|c|c|}
\hline Variables & Duwakot (\%) & Jhaukhel (\%) & Total (\%) \\
\hline $\begin{array}{l}\text { Total participants in a household survey of the village development } \\
\text { committees }\end{array}$ & 60 & 40 & 100 \\
\hline \multicolumn{4}{|l|}{ Caste /ethnic group } \\
\hline Brahmin/Chhetri & 43.1 & 14.1 & 31.5 \\
\hline Newar & 27.7 & 42.5 & 33.6 \\
\hline Other Janajatis & 24.2 & 41.3 & 31.0 \\
\hline Dalit (disadvantaged group) & 5.0 & 2.1 & 3.9 \\
\hline \multicolumn{4}{|l|}{ Wealth quintile based on the acquisition of household facilities } \\
\hline First (poorest) & 25.1 & 24.8 & 25.0 \\
\hline Second & 24.6 & 28.3 & 26.4 \\
\hline Third & 25.1 & 23.7 & 24.4 \\
\hline Fourth (wealthiest) & 25.2 & 23.2 & 24.2 \\
\hline
\end{tabular}




\section{Table 2: Distribution of socioeconomic characteristics of participants and their spouses in the Jhaukhel-Duwakot Health Demographic Surveillance Site}

\begin{tabular}{|c|c|c|c|c|}
\hline \multirow{2}{*}{ Variables } & \multicolumn{2}{|c|}{ Women (participants) } & \multicolumn{2}{|c|}{ Men (Spouse) } \\
\hline & $\mathrm{N}=3,124$ & Percentage & $N=2,673$ & Percentage \\
\hline \multicolumn{5}{|l|}{ Age (years) } \\
\hline$<19$ & 215 & 6.9 & 10 & 0.3 \\
\hline $20-30$ & 1,227 & 39.3 & 650 & 20.8 \\
\hline $31-40$ & 1,143 & 36.6 & 1,157 & 37.0 \\
\hline $41-49$ & 539 & 17.3 & 701 & 22.4 \\
\hline$>50$ & Not included & Not included & 606 & 19.4 \\
\hline \multicolumn{5}{|l|}{ Education level } \\
\hline Illiterate & 667 & 21.4 & 0 & 0 \\
\hline Primary & 332 & 10.6 & 157 & 5.9 \\
\hline Secondary & 370 & 11.8 & 169 & 6.3 \\
\hline Higher secondary and above & 1,755 & 56.2 & 2,347 & 87.8 \\
\hline \multicolumn{5}{|l|}{ Occupation } \\
\hline Agriculture (unpaid work) & 482 & 15.4 & 283 & 10.6 \\
\hline Employed (formal) & 241 & 7.7 & 1,423 & 53.2 \\
\hline Unemployed & 1,901 & 60.9 & 150 & 5.6 \\
\hline Wage earner (informal) & 212 & 6.8 & 359 & 13.4 \\
\hline Business (informal) & 288 & 9.2 & 459 & 17.2 \\
\hline
\end{tabular}

\section{Table 3: Distribution of statements used to assess knowledge of UP of women of reproductive age in the Jhaukhel- Duwakot Health Demographic Surveillance Site $(\mathrm{N}=3,124)$}

\section{Statements (multiple responses)}

\section{Knowledge}

(\%)

1. Carrying heavy loads daily can increase the probability of uterine prolapse

2. Problem of uterine prolapse is more common among women who deliver many children 88.7

3. A symptom of uterine prolapse is the feeling of heaviness or pulling in the pelvis 84.5

4. A best measure to diagnose the problem of uterine prolapse is to go for the check up from health worker 84.4

5. Women of any ages can have the problem of uterine prolapse 64.2

6. Regular exercise can control/stop the uterine prolapse to becoming worse 56.4

7. The best treatment of uterine prolapse is surgery or vaginal hysterectomy 59.5

8. The treatment of the symptoms of uterine prolapse can be done by using a ring pessary 49.7

9. Problem of pelvic organ prolapse (vaginal swelling, uterus, urine bladder or rectum prolapse) is found more in aged women than adult women

10. Doctors can identify the problem of uterine prolapse by blood testing

41.8

11. If the problem of uterine prolapse starts once, it cannot be cured 30.9

12. An obese woman can have less chance of getting the problem of uterine prolapse 
Table 4: Socioeconomic characteristics of women who reported reproductive health problems during household survey and screening camp in the Jhaukhel-Duwakot Health Demographic Surveillance Site

\section{Participants of the household survey reporting} reproductive health problems $(\mathrm{N}=487)$

$\%$

\section{Village development committee}

Duwakot

Jhaukhel

Caste/ethnic group
Brahmin/Chhetri
Newar
Other Janajatis
Dalit

Age group (years)

15-29

30-39

40-59

$\geq 60$

59.7
40.

61.
31.0
5.3
2.5

14.0
36.8
27
22.

59.7

40.3

61.2

31.0

5.3

2.5

14.0

36.8

27.0

22.2
UP screening outreach camp users ( $\mathbf{N}=\mathbf{3 0 3})$

\section{$\%$}

58.0

42.0

50.0

41.3

4.0

4.6

13.2

34.0

25.7

27.1

Table 5: UP prevalence and treatment practices in household survey and clinical diagnosed in UP screening camp in the Jhaukhel-Duwakot Health Demographic Surveillance Site

\begin{tabular}{lcc}
\hline Indicators & Household survey \% $(\mathbf{n = 1 2 4 )}$ & Screening camp users\% $(\mathbf{n}=\mathbf{7 0})$ \\
\hline Surgery & 53.2 & 34.3 \\
Pessary & 11.3 & 37.1 \\
\hline Exercise and medical treatment & 35.5 & 28.6 \\
\hline
\end{tabular}

\section{DISCUSSION}

The results reported here are the first from a populationbased UP prevalence study in a specific community covering all households in the study site. Our findings can be generalized in similar geography and social and cultural contexts.

This study identified self-reported UP prevalence in the JD-HDSS in Nepal's Bhaktapur district. After assessing women's knowledge of UP, we also explored householdwise, self-reported UP prevalence. Our study used UP because women generally perceive that they are affected by UP even when they have POP. Our clinical findings confirmed that women's self-perception and clinical diagnosis of UP and POP overlapped (59.3\%), and we determined UP prevalence in only $25.6 \%$ of camp attendees.

A systematic review of the literature suggests that interview-based surveys provide better information than estimations of morbidity ${ }^{15}$. The validity of selfreported findings is debatable, but a study from Nepal demonstrates that clinical examination confirmed
UP in 207 of 216 self-reporting women, indicating a high correlation between self-reported and clinically diagnosed prolapse ${ }^{1}$. Survey reliability depends upon the level of women's knowledge of UP. Our study assessed women's knowledge, including all symptoms of POP, using the standard tool recommended for assessment of knowledge of UP for population-based studies ${ }^{13}$.

\section{KNOWLEDGE OF UP AND SELF-REPORTED (SYMPTOMATIC) UP PREVALENCE}

Self-reported UP prevalence depends upon women's level of UP knowledge. Nationally, the self-reported prevalence of UP in Nepal is $7 \%{ }^{6}$ and it is $7.6 \%$ in India ${ }^{16}$; in our study, it was $2.11 \%$. Differences in the prevalence of self-reported UP could be due to different levels of UP knowledge and the availability and accessibility of health services for UP management.

We recently determined that $53 \%$ and $37 \%$ of women had ever heard of UP or had comprehensive knowledge of UP, respectively ${ }^{10}$. However, the present study shows that $93 \%$ and $55 \%$ of women had ever heard or had comprehensive knowledge of UP, respectively. These differences might reflect the difference between our 
study site and rural districts of Nepal in the availability of hospitals and a UP screening camp. Women residing in the JD-HDSS might have easy access to health care for UP from NMC and KMC. However, in the national context health facilities and primary care of UP are not integrated with regular reproductive health programmes and referral hospitals are limited to some cities of Nepal ${ }^{10}$.

\section{KNOWLEDGE AND TREATMENT PRACTICES OF UP MANAGEMENT}

In a national household survey, $45 \%$ of women of reproductive age who reported symptoms of UP did not seek medical treatment ${ }^{6}$. In our study, $53 \%$ of women with UP symptoms did not use health care despite exhibiting a high level of UP knowledge and having access to nearby hospitals. A community-based study in north India shows $57 \%$ of women received no treatment. Reasons for not accessing health care include uncooperative family members and lack of time (80.63\%) and lack of money $(74.58 \%)^{16}$. We recently reported that most women in the Dhading district of Nepal do not visit a health facility for UP treatment, mostly because they consider UP a personal problem, feel shame, lack knowledge of medical care or feel inhibited by the cost of treatment and gender role ${ }^{3}$.

\section{REFERENCES}

1. Gurung G, Rana A, Amatya A, Bishta KD, Joshi $A B$, Sayami J. Pelvic organ prolapse in rural Nepalese women of reproductive age groups: what makes it so common. Nep J Obstet Gynaecol. 2007;2:35-41.

2. Thakar R, Stanton S. Management of genital prolapse. BMJ. 2002;324:1258-62.

3. Shrestha B, Onta S, Choulagai B, Poudyal A, Pahari DP, Uprety A, et al. Women's experiences and health care-seeking practices in relation to uterine prolapse in a hill district of Nepal. BMC Women's Health. 2014;14:20.

4. Swift $S$, Woodman $P, O^{\prime}$ Boyle $A$, Kahn M, Valley $M$, Bland D, et al. Pelvic Organ Support Study (POSST): the distribution, clinical definition, and epidemiologic condition of pelvic organ support defects. Am J Obstet Gynecol. 2005;192(3):795-806.

5. Barber DM, Maher C. Epidemiology and outcome assessment of pelvic organ prolapse. Int Urogynecol J. 2013;24:1783-90.

6. Ministry of Health and Population (MoHP) [Nepal], New Era and ICF International Inc: Nepal demographic and health survey 2006. Calverton: MoHP, New Era and ICF International Inc; 2007.

\section{CONCLUSION}

In JD-HDSS, women with knowledge of UP are almost double that reported by the national survey. Similarly, self-reported UP prevalence in JD-HDSS is almost threefold less than the national prevalence. UP knowledge, early healthcare practices and availability of surgical care of UP might contribute to these findings.

\section{ACKNOWLEDGEMENT}

We thank the JD-HDSS project for support during the follow up survey in Jhaukhel and Duwakot HDSS and the UP screening outreach camp. Special thanks to Dr. Abhinav Vaidya, Dr. Umesh Aryal and Dr. Muni Raj Chhetri for their support during study planning, training of field workers, supervision of field work and data analysis. We are grateful to Nepal Medical College and Kathmandu Medical College for providing the venue for the outreach camp, including support from gynaecologists. We acknowledge the Rural Health and Education Trust (RHEST) for logistic support during the UP outreach camps. The University of Gothenburg provided travel funds to BS through a "Global University" grant. We thank scientific editor Karen Williams (Kwills Editing Services, Weymouth, MA, USA) for providing professional English-language editing of this article.

7. Darshan A. Prevalence of uterine prolapse amongst gynaecology OPD patients in Tribhuvan university teaching hospital in Nepal and its sociocultural determinants. Safe Motherhood Network Federation (SMNF), Beyond Beijing Committee (BBC). Kathmandu: Tribhnuvan University Teaching Hospital (TUTH); 2009.

8. Bonetti TR, Erpelding A, Pathak LR. Listening to "felt needs": investigating genital prolapse in Western Nepal. Reprod Health Matters. 2004;12:166-75.

9. Lamichhane $\mathrm{P}$, Tiwari S. Progress report on the Aama/4 ANC Demand side Financing Program, strengthening health system- Improving Services. NHSSP [Nepal]; 2012

10. Shrestha B, Devkota B, Khadka BB, Choulagai B, Pahari DP, Onta $S$, et al. Knowledge on uterine prolapse among married women of reproductive age in Nepal. Int J Women's Health. 2014; 6:771-9.

11. Radl MC, Rajwar R, Arja R,Aror A. Uterine prolapse prevention in Eastern Nepal: the perspectives of women and health care professionals. Int J Women's Health. 2012;4:373-82.

12. Aryal UR, Vaidya A, Shakya-Vaidya S, Petzold M, Krettek A. Establishing a health demographic surveillance site in Bhaktapur district, Nepal: 
initial experiences and findings. BMC Res Notes. 2012;5:489.

13. Shah AD, Kohli N, Rajan SS, Braaten KP, Massagli MP, Hoyte L. A reliable, valid instrument to assess patient knowledge about urinary incontinence and pelvic organ prolapse. Int Urogynecol J Pelvic Floor Dysfunct. 2008;19(9):1283-9.

14. Chen GD. Updated definition of female pelvic organ prolapse. Incont Pelvic Floor Dysfunct. 2007;1:121

4.
15. Sadana R. Measuring reproductive health: Review of community-based approaches to assessing morbidity. Bull World Health Organ. 2000;78(5):64054.

16. Walia SK, Singh A. Self-reported uterine prolapse in a resettlement colony of north India. J Midwifery Women's Health. 2000; 45(4): 343-50. 